\author{
PATRYK PLESKOT \\ Instytut Pamięci Narodowej \\ Państwowa Wyższa Szkoła Zawodowa w Oświęcimiu
}

\title{
MODA ZA ŻELAZNĄ KURTYNĄ. REFLEKSJE WOKÓE KSIĄŻKI ANNY PELKI O MODZIE MŁODZIEŻOWEJ W POLSKIEJ RZECZYPOSPOLITEJ LUDOWEJ I NIEMIECKIEJ REPUBLICE DEMOKRATYCZNEJ*
}

\begin{abstract}
Abstrakt: Historia mody młodzieżowej za żelazną kurtyną (i szerzej - analiza kultury młodzieżowej w okresie „realnego socjalizmu") nie jest dziewiczym obszarem badawczym w naukach społecznych, zarówno polskich, jak i niemieckich. Główną zaletą opracowania Anny Pelki Z [politycznym] fasonem. Moda młodzieżowa $z$ PRL $i$ NRD, Gdańsk 2014 jest perspektywa porównawcza w analizowaniu tego zagadnienia. Autem książki jest też dojrzałość badawcza Autorki, która rozumie, że moda ściśle wiązała się z kontekstem społeczno-politycznym, w którym przyszło żyć mieszkańcom NRD i PRL.
\end{abstract}

Słowa kluczowe: moda młodzieżowa, NRD, PRL, subkultura, sondaż.
Abstract: The history of youth fashion behind the Iron Curtain (and more extensively - an analysis of youth fashion at the time of "real socialism") is but no means an unexplored field in the social sciences, both Polish and German. The prime asset of the publication by Anna Pelka: Z [politycznym] fasonem. Moda młodzieżowa z PRL i NRD (Gdańsk 2013) is its comparative perspective of analysing the titular topic. Another merit is the research maturity of the author who appreciates that fashion was closely linked with the socio-political context in which the population of People's Poland and the GDR lived.

Keywords: youth fashion, DDR, Polish Peoples' Republic, subculture, survey.

Historia mody młodzieżowej za żelazną kurtyną (i szerzej - analiza kultury młodzieżowej w okresie „realnego socjalizmu”) nie jest dziewiczym obszarem w badaniach historyków, socjologów, a nawet psychologów, zarówno polskich, jak i niemieckich. Wśród tych pierwszych można znaleźć m.in. opracowania

* Anna Pelka, Z [politycznym] fasonem. Moda młodzieżowa w PRL i NRD, Gdańsk 2013, słowo/obraz terytoria, ss. 362 . 
Hanny Świdy-Ziemby lub psychologa Piotra Szaroty ${ }^{1}$, a wśród tych drugich artykuły Corduli Günther, Philippa Heldmanna, leksykon Günthera Höhne czy prace Ingrid Loschek i Rebekki Menzel ${ }^{2}$. Wątki ubioru młodzieży podjęła też sama Autorka recenzowanej książki w jednej ze swych poprzednich publikacji dobrze przyjętej pracy Teksas-land ${ }^{3}$.

Czy zatem kolejna książka w tej dziedzinie wnosi do stanu badań coś nowego? Odpowiedź na to pytanie jest twierdząca, a przyczynia się do tego nie tylko szeroka kwerenda, przeprowadzona przez Autorkę w dwudziestu placówkach polskich i niemieckich, wzbogacona kilkudziesięcioma relacjami świadków epoki, ale również - a może przede wszystkim - porównawczy charakter rozważań, zestawiający rzeczywistość Polski Ludowej i Niemiec wschodnich w całym okresie 1945-1989. Narzuca tu się zresztą drobna uwaga: zakres chronologiczny nie został podany w tytule, co może rodzić pewne nieporozumienia; zwłaszcza że użyte w nagłówku skróty „PRL” i „NRD” sugerują wzięcie pod uwagę nieco węższego przedziału czasowego. Autorka przyjęte ramy chronologiczne uznała za na tyle oczywiste, że nie postanowiła wyjaśnić ich zastosowania we wstępie.

Chociaż narracja nie unika pewnych powtórzeń w stosunku do istniejącej już literatury, a jej rozumienie pojęcia "mody” jest wąskie (skupia się na tym, co było modne i odbiegało od społecznej normy), to jednak ta komparatystyczna perspektywa jest głównym atutem książki. Anna Pelka należy do tego pokolenia badaczy, które skorzystało z przynależności Polski do Unii Europejskiej i w prowadzeniu kariery naukowej nie było hamowane granicami państwowymi. Studia w Polsce i Niemczech (a także w Hiszpanii) sprawiły, że równie swobodnie porusza się w tematyce polskiej, jak i niemieckiej. Ta podwójna specjalizacja stanowi najmocniejszą stronę badaczki.

Publikacja została podzielona na siedem rozdziałów, poprzedzonych wstępem, a uwieńczonych krótkim epilogiem. Każda z głównych części dzieli się na kilka podrozdziałów. Narracja została zasadniczo skonstruowana według porządku chronologicznego, niemniej wewnątrz poszczególnych rozdziałów a niekiedy nawet podrozdziałów - Pelka płynnie przechodzi od zagadnień polskich do niemieckich i odwrotnie.

Najbardziej pobieżnie został potraktowany okres 1945-1959. Wynika to nie tyle z faktu późnego powstania Niemieckiej Republiki Demokratycznej

${ }^{1}$ H. Świda-Ziemba, Młodzież PRL. Portrety pokoleń w kontekście historii, Kraków 2010; P. Szarota, Od skarpetek Tyrmanda do krawata Leppera. Psychologia stroju dla średnio zaawansowanych, Warszawa 2008.

${ }^{2}$ C. Günther, „Präsent 20” - Der Stoff, aus dem die Träume sind, w: Wunderwirtschaft. DDR-Konsumkultur in den 60er Jahren, red. Neue Gesellschaft für Bildende Kunst, Köln 1996; P. Heldmann, Konsumpolitik in der DDR. Jugendmode in den sechziger Jahren, w: Konsumpolitik. Die Regulierung des privaten Verbrauchs im 20. Jahrhundert, red. H. Berghoff, Göttingen 1999; G. Höhne, Das große Lexikon DDR-Design, Köln 2008; I. Loschek, Mode im 20. Jahrhundert. Eine Kulturgeschichte unserer Zeit, München 1990; R. Menzel, Jeans in der DDR. Vom tieferen Sinn einer Freizeithose, Berlin 2004.

${ }^{3}$ A. Pelka, Teksas-land. Moda młodzieżowa w PRL, Warszawa 2007. 
(w 1949 r.), ile z tego, że do momentu odwilży trudno jest mówić o modzie młodzieżowej jako zjawisku społecznym (jak to wynika z argumentacji Autorki, s. 10-33). Może więc wyszłoby książce na dobre wyodrębnienie w osobną część podrozdziału poświęconego politycznej „odwilży”, w różnym stopniu objawiającej się w obu państwach (s. 32-52)?

Zabieg ten byłby zasadny o tyle, że właśnie wtedy uwidoczniło się zjawisko, które pozostanie już obecne w historii obu krajów co najmniej do 1989 r.: ciągłych „przetargów symbolicznych” między wymogami ideologii komunistycznej (na bieżąco interpretowanej przez aparat partyjno-państwowy) a wpływem kultury zachodniej. Skutkiem takich „przetargów” było chociażby propagowanie przez pismo „Uroda” mody inspirowanej włoskim neorealizmem (s. 48). Drugim fenomenem, obecnym w różnym nasileniu w całej analizowanej przez Pelkę okresie, była różnica w zakresie wolności między polską a wschodnioniemiecką modą młodzieżową. Fakt ten nie jest zapewne zaskakujący, ale został tutaj należycie uargumentowany. Jak pisze Autorka, ,podczas gdy młodzi Polacy (w tym młodzi projektanci) zerkali w stronę Francji, młodzi Niemcy, odseparowani murem od Europy, spoglądali między innymi w stronę Polski" (s. 6).

Dwa kolejne rozdziały zostały poświęcone dekadzie lat sześćdziesiątych, odpowiednio w Polsce i NRD. Najciekawszym chyba opisanym tu wątkiem, zyskującym porównawczy wymiar, jest syzyfowa praca centralnie zarządzanej infrastruktury odzieżowej obu państw (od instytutów wzornictwa po fabryki), usiłującej reagować (nie tylko zresztą pozytywnie) na zmieniające się jak w kalejdoskopie trendy zachodnie i udowodnić, że "my też potrafimy”. Autorka plastycznie pokazuje, że - zwłaszcza w NRD - władze niezwykle poważnie podchodziły do mody, traktując ją jako kolejny front zimnej wojny i wojny psychologicznej. Skoro w USA i Republice Federalnej Niemiec tworzono nowe tkaniny sztuczne, swój nylon musieli mieć Polacy, a dederon (od Deutsche Demokratische Republik) czy „Präsent 20" (czyli prezent na dwudziestolecie NRD) - wschodni Niemcy (s. 134).

W podobny sposób zostały skonstruowane następne cztery rozdziały, poświęcone latom siedemdziesiątym i osiemdziesiątym w dwóch krajach „realnego socjalizmu". I tutaj Pelka dochodzi do ciekawych konkluzji, dostrzegając chociażby równoległy kryzys na rynku odzieżowym w NRD i PRL w drugiej połowie lat siedemdziesiątych, związany m.in. z zadłużeniem zagranicznym obu państw (s. 152), czy też różnice w postrzeganiu fenomenu dyskotek: być może w nieco zbyt uproszczony sposób Pelka przekonuje, że o ile w NRD dyskoteki były istotnym elementem debaty politycznej wewnątrz kierownictwa partyjno-państwowego, o tyle w Polsce "ta forma zabawy pozostała rozrywką poza politycznym dyskursem" (s. 218).

Chociaż po części zasadniczej następuje epilog, brakuje nieco syntetycznego podsumowania całości rozważań. Zamiast tego Pelka skupia się na skrótowym pokazaniu, co stało się z modą po transformacji 1989 r. Co istotne, zwraca uwagę, że upadek żelaznej kurtyny wcale nie oznaczał natychmiastowego i swobodnego przepływu nurtów mody między Wschodem a Zachodem. Również od strony instytucjonalnej „proces emancypowania się mody był długi i bolesny” (s. 282). 
Analizy tekstu nie ułatwiają umieszczone na końcu przypisy i częste luki $\mathrm{w}$ paginacji, ale z wyjątkiem recenzentów czytelnikom nie powinno to przeszkadzać; opcja z przypisami końcowymi ułatwia zaś lekturę tekstu głównego.

Zwraca uwagę dopracowanie wizualne i redakcyjne książki. Ciekawie skonstruowane tytuły i śródtytuły, motta, trafne puenty i przemyślana logika wywodu (wyrażająca się chociażby w płynności przechodzenia z wątków polskich na niemieckie i odwrotnie) świadczą o dużej pracy, jaką włożyła Autorka w zaprezentowanie wyników swych badań. Zarazem przejrzysty układ graficzny, trafny rozkład fotografii i staranność wydawnicza dają dobre świadectwo komercyjnemu domowi wydawniczemu, który nie zdecydował się na wprowadzenie oszczędności kosztem jakości redakcji.

Żywy język, jakim posługuje się Autorka, należy do głównych atutów książki. Nie chodzi tu tylko o samą formę i styl. Pelka sprawnie posługuje się perspektywą porównawczą, a przede wszystkim potrafi celnie wpleść wątki mody młodzieżowej w szerszą optykę badawczą. Zdaje sobie sprawę, że owa moda organicznie wiązała się z tematyką polityczną, kulturalną, społeczną; stanowiła przejaw kontekstu społeczno-politycznego, w którym przyszło żyć mieszkańcom NRD i PRL. Dlatego też szczegółowe nieraz opisy ubiorów niepostrzeżenie stają się elementem skomplikowanych wywodów na temat zagadnień polityki państwowej, działania opozycji, przemian kulturowych czy zjawiska kultury niezależnej. Autorka rozumie, że moda nie istniała w próżni i była tylko (i aż) jednym z wymiarów ówczesnej rzeczywistości.

Tematy mody zostały więc potraktowane jako część historii kultury i kontrkultury, ewolucji seksualności i postrzegania płci, jeden z tematów propagandy i cenzury, jedna z bolączek gospodarki nakazowo-rozdzielczej, wreszcie jako klucz do badania sfer wolności w państwach o totalistycznych tendencjach a wszystko to zanurzone w „porównawczym sosie”. Ów klucz pozwala Autorce penetrować tak z pozoru oddalone od siebie obszary, jak np. centralne plany gospodarcze, produkcja specjalistycznych tkanin, światowe dni młodzieży, zjawisko emigracji, koncerty The Rolling Stones i subkultura punkowców. W swych badaniach wczytuje się w przemówienia decydentów politycznych, obrady koncesjonowanych organizacji młodzieżowych, artykuły prasy młodzieżowej i specjalistycznej, wsłuchuje się w relacje świadków i utwory muzyczne, ogląda filmy fabularne i dokumentalne. Taka różnorodność nie sprawia przy tym wrażenia pomieszania i chaosu.

W ten sposób Pelka wpisuje się w bardzo owocny i godny poparcia nurt polskiej historiografii, podchodzący do najnowszej historii Polski (i nie tylko) niejako „od dołu”: nie od najważniejszych wydarzeń i ewolucji politycznej, lecz od drugorzędnych z pozoru zjawisk społecznych, poprzez które owa „wielka historia” zyskuje nowy wymiar i bogaty kontekst. Takie ujęcie było wyróżniającą cechą większości prac wydanych w ramach nieistniejącej już niestety serii $W$ krainie $P R L^{4}$.

${ }^{4}$ Zob. np. A. Gajewski, Polski film sensacyjno-kryminalny (1960-80), Warszawa 2008; J. Kochanowicz, ZMP w terenie. Stalinowska próba modernizacji opornej rzeczywistości, 
Autorka nie popełnia przy tym błędu, o który dość łatwo w tego typu nastawieniu badawczym. Nietrudno bowiem tutaj popaść w anegdotę, postawę nostalgii czy wyliczanie ciekawostek. Tymczasem Pelka z wyczuciem balansuje między poetyką tekstu naukowego a narracją przeznaczoną dla masowego czytelnika: unikając mielizn płytkiej efektowności i upraszczających skrótów, potrafi na ogół zachować barwność stylu, a jednocześnie nie popada w koturnowe (nomen omen) tony.

To ogólne wrażenie nie może przesłonić pewnych drobnych i drugorzędnych, ale jednak dostrzegalnych mankamentów stylistyczno-językowych. Chwilami czytelnik może się poczuć nieco znużony kolejnymi drobiazgowymi opisami poszczególnych elementów stroju. To oczywiście kwestia subiektywna i uzależniona od zainteresowań odbiorcy. Z nieco większym obiektywizmem można zwrócić uwagę, że mimo dbałości o język, Pelka z rzadka wpada w ton kolokwialny. Zwracają uwagę bardzo na szczęście nieliczne nieścisłości czy wręcz błędy faktograficzne, np. określenia w rodzaju „faszystowskie gestapo" (s. 116); „nowego (od grudnia 1970 roku) sekretarza partii Edwarda Gierka” (s. 182); nazwanie lat siedemdziesiątych epoką kolorowej telewizji (s. 182)5 ; bezkrytyczne przytoczenie stwierdzenia Świdy-Ziemby, że w konsekwencji marca 1968 r. młodzież ostatecznie utraciła wiarę w socjalizm (s. 195)6. Pelce zdarza się z rzadka zawrzeć uogólniające i aprioryczne uwagi, dla których brak konkretnego potwierdzenia. Mianowicie skąd bierze się pewność, że „nowo utworzone na gruzach ZMP organizacje młodzieżowe [--] dla większości młodych Polaków nie były atrakcyjne" (s. 52)? Zarówno Związek Młodzieży Socjalistycznej, jak i Związek Młodzieży Wiejskiej były przecież organizacjami masowymi. Przesadne jest także stwierdzenie odnoszące się do czasów „małej stabilizacji”, w których rzekomo „wszelkie przejawy samodzielnego myślenia i indywidualnej kreatywności były tępione” (s. 60). Podobnie należałoby ocenić następujące słowa: „wszystko bowiem było modne i dozwolone” (s. 260); „Polacy diametralnie różnią się od Niemców mentalnością” (s. 282) czy też te na temat „głębokiego polskiego tradycjonalizmu wraz z jego zachowawczym wizerunkiem kobiety" (s. 282). Ponadto we fragmentach dotyczących emigracji warto byłoby przytoczyć najważniejszą dla tego tematu książkę Dariusza Stoli Kraj bez wyjścia??

Pelka zbyt chyba ufnie podchodzi do sondaży z epoki (albo przynajmniej nie dzieli się z czytelnikami warsztatowymi uwagami co do wiarygodności tego

Warszawa 2000; K. Kosiński, Nastolatki '81. Świadomość młodzieży w epoce „Solidarności”, Warszawa 2002; A. Leszczyński, Sprawy do załatwienia. Listy do „Po Prostu” 1955-1957, Warszawa 2000; Zbudować Warszawę piękna... O nowy krajobraz stolicy (1944-1956), red. J. Kochanowski, Warszawa 2003.

${ }^{5}$ W rzeczywistości kolorowa telewizja dopiero wchodziła wówczas do użytku i do końca dekady jej zasięg był nieporównywalny z telewizją czarno-białą, zob. P. Pleskot, Wielki mały ekran. Telewizja a codzienność Polaków w latach sześćdziesiatych, Warszawa 2007, s. 44-45.

${ }^{6}$ Por. H. Świda-Ziemba, op. cit., s. 501-502.

7 D. Stola, Kraj bez wyjścia? Migracje z Polski 1949-1989, Warszawa 2010. 
typu badań). Choć stanowią one cenne źródło historyczne, należy pamiętać, że w niedemokratycznej rzeczywistości respondenci bardziej niż w państwach demokratycznych skłonni byli obierać określone strategie wobec instytucji sondażowych, niekoniecznie zbieżne z ich rzeczywistymi poglądami. Należałoby więc skomentować cytowane za sondażami Ośrodka Badania Opinii Publicznej dane, jak np. te, że tylko 25,3 proc. respondentów przyznawało się w $1963 \mathrm{r}$. do robienia zakupów w ośrodkach prywatnej inicjatywy (s. 59). Komentarza odautorskiego w jeszcze większym stopniu domagają się wyniki ankiety zleconej przez Instytut Mody w NRD w 1979 r., w której młodzi ludzie zapewniali, że ubiór nie jest wskazówką orientacji politycznej. Trudno przecież oczekiwać, by stwierdzili coś innego (s. 174).

Narracja Autorki w większej mierze skupia się na kobietach niż mężczyznach (zob. np. s. 160-161). Pelka nie roztrząsa jednak problemu, czy bycie modnym było ważniejsze dla kobiet czy dla mężczyzn. Ta dysproporcja może na to wskazywać, jednak sprawa ta nie jest wyjaśniona w samym tekście. Autorka mogłaby również nieco więcej miejsca poświęcić niedocenianemu w należytym stopniu zjawisku pomocy materialnej z Zachodu (s. 242). Warto pokusić się o głębsze zbadanie wpływu tej pomocy na możliwości kompletowania pożądanego stroju przez polską i wschodnioniemiecką młodzież, choć precyzyjne określenie jej wartości materialnej wymagałoby żmudnych i czasochłonnych poszukiwań ${ }^{8}$.

Podkreślmy jednak wyraźnie, że powyższe uwagi nie obniżają ogólnie wysokiej wartości książki. Dostrzegłem jednak jeden poważny problem w koncepcji tego opracowania, który w pewien sposób rzutuje na jego ostateczną ocenę. Otóż w rozważaniach Pelki można natrafić na takie np. słowa: „bohaterami mojej książki są młodzi ludzie, konsumenci mody młodzieżowej” (s. 5); „największym hitem mody młodzieżowej tej dekady była jednak «koszula dziadka»" (s. 217); „oprócz dżinsów, luźnych swetrów i koszul flanelowych w kratę typowy był styl wojskowy” (s. 223); „,był to styl dość powszechny w dużych miastach NRD” (s. 266); czy też „młodzi ludzie zajmowali się wytwarzaniem różnych artykułów i przedmiotów głównie z powodów finansowych" (s. 274).

Zasadniczą wadą tego typu zwrotów i wyrażeń jest ich liczbowe i statystyczne zawieszenie w próżni. O jakiej tak naprawdę grupie mówi Autorka? Kogo ma na myśli, pisząc „Polki”, „młodzież”, „czytelniczki” itp.? Jak liczna jest owa „modna młodzież"? Co to znaczy, że dany ubiór jest „hitem” lub jest „typowy” albo „dość powszechny”? Jakiego procentu społeczeństwa polskiego i niemieckiego tak naprawdę dotyczą rozważania i analizy dotyczące „modności” danego

${ }^{8}$ Nie są one niemożliwe, np. szacuje się, że Polonia australijska w latach osiemdziesiątych rokrocznie przesyłała do Polski pomoc o łącznej wartości nawet 10 mln dolarów australijskich, 10 milionów dolarów rocznie. Pomoc australijskiej Polonii dla Polski, „Tygodnik Polski" (Sydney), 1987, nr 43, s. 13. Szacunki te opierano na informacjach uzyskanych od firm obsługujących wysyłkę paczek. 
ubioru? Jaki był nakład czasopism modowych? Jeśli nie istnieją statystyki pozwalające na sprecyzowanie przedmiotu badań, to należałoby przynajmniej o tym napisać i podzielić się z czytelnikami trudnościami definicyjnymi. Bodajże raz tylko Pelka przyznaje, wieńcząc jeden z opisów trendów wytyczanych przez polską prasę modową: ,trudno ocenić, na ile te egzotyczne stylizacje przyjęły się wśród polskiej młodzieży" (s. 207). Stwierdzenie to wypadałoby odnieść praktycznie do każdego punktu, w którym Autorka wywodzi, że coś było modne i upowszechnione (bądź nie) wśród młodzieży.

Pytania te i wątpliwości można rozszerzyć: od kiedy dany produkt staje się modny, a do którego momentu pozostaje tylko awangardowy? Pelka pisze zresztą i o tym, omawiając z jednej strony np. masowość dżinsów (s. 200-202), a z drugiej opisując wymyślne niekiedy i jednorazowe kreacje projektantów (s. 236-239) czy specyficzny styl ubierania się subkultur, a także np. niewielkich grup polskich aktywistów opozycyjnych po 13 grudnia 1981 r. (s. 223-230). Następuje w ten sposób pewne wymieszanie porządków, którego zasadność nie zawsze jest czytelna.

Co więcej: czy modne jest to, co stwierdzą dyktatorzy mody, czy to, jak modę definiuje praktyka społeczna? Obie interpretacje są uprawnione, warto byłoby jednak zdecydować się na jedną z nich lub też sprecyzować, co w danym momencie narracji bierze się pod uwagę. Tymczasem nie wiemy np., w jakim stopniu zalecenia Barbary Hoff wpływały na sposób noszenia się młodych mieszkańców Polski. Autorka nie proponuje zatem definicji „modności” (w owym wąskim znaczeniu tego pojęcia) i określenia swego rodzaju społecznej masy krytycznej, przekroczenie której powoduje, że dana rzecz zasługuje na miano modnej.

Pelka nie dokonuje ponadto kolejnego ważnego rozróżnienia na jeszcze innej płaszczyźnie. Po pierwsze: jaki procent młodych ludzi zainteresowanych ubieraniem się zgodnie z zaleceniami projektantów był w stanie zrealizować te aspiracje? Autorka nieraz słusznie podkreśla olbrzymie trudności ze zdobyciem nawet podstawowych artykułów. I chociaż jeden z podrozdziałów nosi tytuł „Co modne - co realne", to jednak nie znajdziemy w nim pełnej odpowiedzi na tak postawione pytanie. Powtórzmy: być może jej udzielenie nie jest wobec ograniczeń źródłowych możliwe, niemniej należałoby to stwierdzić. Po drugie: jaki procent ogółu społeczeństwa stanowiły owe zainteresowane osoby? W ten sposób powracamy do punktu wyjścia.

Głębsza kwerenda w źródłach wytworzonych przez Służbę Bezpieczeństwa i jej enerdowską odpowiedniczkę, czyli STASI, mogłaby okazać się pomocna w szukaniu danych statystycznych. Tymczasem historyczka w bibliografii podaje, że w archiwum Instytutu Pamięci Narodowej skorzystała z zespołu... Ministerstwa Spraw Wewnętrznych, co świadczy o słabym rozeznaniu w specyfice tego archiwum. Brakuje też informacji, by Autorka wykorzystała dokumentację STASI, przechowywaną w BStU (Der Bundesbeauftragte für die Unterlagen des Staatssicherheitsdienstes der ehemaligen Deutschen Demokratischen Republik) ${ }^{9}$.

${ }^{9}$ Zob. http://www.bstu.bund.de/DE/Home/home_node.html [dostęp: 1 IX 2014]. 
Pomimo powyższych wątpliwości książka Anny Pelki zasługuje na pozytywną ocenę i uznanie. Wiedza badaczki, komparatystyczne ujęcie i sprawność językowa sprawiają, że opracowanie to ma zdecydowanie więcej zalet niż wad. Te ostatnie mogą zaś stanowić dogodny pretekst do dalszych poszukiwań, do których warto Autorkę zachęcać.

\section{Streszczenie}

Historia mody młodzieżowej za żelazną kurtyną (i szerzej - analiza kultury młodzieżowej w okresie „realnego socjalizmu”) nie jest dziewiczym obszarem badawczym w naukach społecznych, zarówno polskich, jak i niemieckich. Główną zaletą opracowania Anny Pelki Z [politycznym] fasonem. Moda młodzieżowa z PRL i NRD, Gdańsk 2014 jest perspektywa porównawcza w analizowaniu tego zagadnienia. Autem książki jest też dojrzałość badawcza Autorki, która rozumie, że moda ściśle wiązała się z kontekstem społeczno-politycznym, w którym przyszło żyć mieszkańcom NRD i PRL. Dlatego też szczegółowe nieraz opisy ubiorów niepostrzeżenie stają się elementem skomplikowanych zagadnień z obszaru polityki państwowej, działania opozycji, przemian kulturowych czy zjawiska kultury niezależnej.

Tematy mody zostały więc potraktowane jako część historii kultury i kontrkultury, ewolucji seksualności i postrzegania płci, jeden z tematów propagandy i cenzury; jedna z bolączek gospodarki nakazowo-rozdzielczej; wreszcie jako klucz do badania sfer wolności w państwach o totalistycznych tendencjach - a wszystko to zanurzone zostało w porównawczym sosie. Ów klucz pozwala autorce penetrować tak z pozoru oddalone od siebie obszary jak np. centralne plany gospodarcze, produkcja specjalistycznych tkanin, światowe dni młodzieży, zjawisko emigracji, koncerty The Rolling Stones i subkultura punkowców.

W ten sposób Pelka wpisuje się w bardzo owocny i godny poparcia nurt polskiej historiografii, podchodzący do najnowszej historii Polski niejako „od dołu”: nie od najważniejszych wydarzeń i ewolucji politycznej, lecz od drugorzędnych z pozoru zjawisk społecznych, poprzez które owa „wielka historia” zyskuje nowy wymiar i bogaty kontekst.

\section{Fashion behind the Iron Curtain. Reflections on a Book by Anna Pelka about Youth Fashion in the People's Republic of Poland and the German Democratic Republic}

The history of youth fashion behind the Iron Curtain (and more extensively - an analysis of youth fashion at the time of "real socialism") is but no means an unexplored field in the social sciences, both Polish and German. The prime asset of the publication by Anna Pelka: Z [politycznym] fasonem. Moda młodzieżowa z PRL i NRD 
(Gdańsk 2014) is its comparative perspective of analysing the titular topic. Another merit is the research maturity of the author who appreciates that fashion was closely linked with the socio-political context in which the population of People's Poland and the GDR lived. This is the reason why the at times detailed descriptions of clothes imperceptibly turned into an element of complex problems from the realm of state policy, the activity of the opposition, cultural transformations or assorted phenomena of independent culture.

The topic of fashion has thus been treated as part of the history of culture and counter-culture, the sexual revolution and the perception of sex, as well as one of the themes of propaganda and censorship and the problems faced by the command-and-quota economy, and, finally, as a key for studying the enclaves of freedom in states disclosing totalistic tendencies; the author immersed all these components in a comparative approach. This key also permitted her to penetrate such ostensibly distant domains as central economic plans, the production of special textiles, world youth days, emigration, The Rolling Stones concerts, and punk sub-culture.

In this manner Pelka has become part of an extremely prolific current of Polish historiography, worth supporting and approaching the latest history of Poland as if from a grass-roots level, i.e. involving not the most significant events and political evolution but the, at first glance, secondary social phenomena thanks to which "great history" gains a new dimension and an extensive context.

Translated by Aleksandra Rodzińska-Chojnowska

\section{Bibliografia}

Gajewski, Arkadiusz. Polski film sensacyjno-kryminalny (1960-80). Warszawa: Trio, 2008. Günther, Cordula. „«Präsent 20» - Der Stoff, aus dem die Träume sind”. W Wunderwirtschaft. DDR-Konsumkultur in den 60er Jahren, red. Neue Gesellschaft für Bildende Kunst, 144-151. Köln: Böhlau Verlag, 1996.

Heldmann, Philipp. „Konsumpolitik in der DDR. Jugendmode in den sechziger Jahren". W Konsumpolitik. Die Regulierung des privaten Verbrauchs im 20. Jahrhundert, red. Hartmut Berghoff, 135-158. Göttingen: Vandenhoeck \& Ruprecht, 1999.

Höhne, Günter. Das große Lexikon DDR-Design. Köln: Komet Verlag, 2008.

Kochanowicz, Joanna. ZMP w terenie. Stalinowska próba modernizacji opornej rzeczywistości. Warszawa: Trio, 2000.

Kochanowski, Jerzy, red. Zbudować Warszawę piękna... O nowy krajobraz stolicy (19441956). Warszawa: Trio, 2003.

Kosiński, Krzysztof. Nastolatki '81. Świadomość młodzieży w epoce „Solidarności”. Warszawa: Trio, 2002.

Leszczyński, Adam. Sprawy do załatwienia. Listy do „Po Prostu” 1955-1957. Warszawa: Trio, 2000.

Loschek, Ingrid. Mode im 20. Jahrhundert. Eine Kulturgeschichte unserer Zeit. München: Bruckmann, 1990.

Menzel, Rebecca. Jeans in der DDR. Vom tieferen Sinn einer Freizeithose. Berlin: Ch. Links Verlag, 2004. 
Pelka, Anna. Teksas-land. Moda młodzieżowa w PRL. Warszawa: Trio, 2007.

Pelka, Anna. Z [politycznym] fasonem. Moda młodzieżowa z PRL i NRD. Gdańsk: słowo/ obraz terytoria, 2013.

Pleskot, Patryk. Wielki mały ekran. Telewizja a codzienność Polaków w latach sześćdziesiatych. Warszawa: Trio, 2007.

Stola, Dariusz. Kraj bez wyjścia? Migracje z Polski 1949-1989. Warszawa: IPN, ISP PAN, 2010.

Szarota, Piotr. Od skarpetek Tyrmanda do krawata Leppera. Psychologia stroju dla średnio zaawansowanych. Warszawa: Wydawnictwa Akademickie i Profesjonalne, 2008.

Świda-Ziemba, Hanna. Młodzież PRL. Portrety pokoleń w kontekście historii. Kraków: Wydawnictwo Literackie, 2010.

Biogram: Patryk Pleskot - dr hab., prof. nadzwyczajny w Państwowej Wyższej Szkole Zawodowej w Oświęcimiu, główny specjalista w warszawskim oddziale Instytutu Pamięci Narodowej, historyk, politolog; interesuje się najnowszą historią polityczną Polski i świata, historią społeczną PRL; e-mail: patryk.pleskot@ipn.gov.pl. 